\title{
Forecasting inflation in Malaysia
}

\begin{abstract}
This paper aims to identify the best indicator in forecasting inflation in Malaysia. In methodology, the study constructs a simple forecasting model that incorporates the indicator/variable using the vector error correction (VECM) model of quasi-tradable inflation index and selected indicators: commodity prices, financial indicators and economic activities. For each indicator, the forecasting horizon used is 24 months and the VECM model is applied for seven sample windows over sample periods starting with the first month of 1980 and ending with the 12th month of every 2 years from 1992 to 2004. The degree of independence of each indicator from inflation is tested by analyzing the variance decomposition of each indicator and Granger causality between each indicator and inflation. We propose that a simple model using an aggregation of indices improves the accuracy of inflation forecasts. The results support our hypothesis.
\end{abstract}

Keyword: Inflation forecaster; VECM model; Malaysian economy 